\title{
Mining Data for Student Success
}

\author{
Libby V. Morris ${ }^{1}$
}

Published online: 8 April 2016

(C) Springer Science+Business Media New York 2016

The landscape of higher education is changing as legislatures, foundations, governing boards, federal and state agencies, and potential students (and other consumers) ask specific questions about retention and graduation, student debt, learning and workforce preparedness, quality of institutions, and relevance of academic programs, as well as the cost of it all. Multiple external constituents, along with college administrators and faculty members, want and need better data to inform decision making.

The need to use data to answer important questions about student enrollment, faculty ranks and distribution, and revenue and expenditures was recognized more than 50 years ago with the founding of the Association for Institutional Research (AIR) (https://www.airweb.org/ pages/default.aspx). In the early years, a lot of counting was done, numbers were aggregated, and tables and reports were issued. Much less frequent were analyses of the intersection of disparate data sets to yield information for operational and strategic planning. Institutional researchers often came from the faculty and represented people who liked working with data and ensuring its integrity. As the demands for compliance reporting and accountability increased, a career path evolved, and so did the number of people working in institutional research. Today AIR has more than 4,700 members and more than 1,600 member institutions. These institutional offices vary in size, ranging from 1 to 2 professionals to offices with 6 or more staff members. Multiple surveys reveal that most institutional research offices are dominated by ongoing compliance activities, including IPEDS (Integrated Postsecondary Education Data System) reporting, supplying data for regional and specialized accreditation, and meeting other state and federal reporting requirements. Consequently, assuming leadership for more analytical work is beyond the capacity, and perhaps the expertise, in all but those offices that are highly staffed.

Higher education institutions are awash in data; yet the ability to convert data to useful information has not kept pace with the needs from internal and external constituents. At one time, the institutional research office was THE data office, but increasingly other offices including such entities as the registrar, financial aid, student affairs, admissions, and the budget offices - collect and maintain student and university level data. Analyzing these data sets is

Libby V. Morris

lvmorris@uga.edu 
essential to address important questions about student learning outcomes, advising, funding, new pedagogical approaches, and program effectiveness overall. The suggestion is not that this is easy work that is merely left undone. Rather, understanding where the leverage points are in institutional policies and practices to increase student success is complicated, far more so than calculating graduation and retention rates, although those activities are quite difficult considering the mobility of the student population and the overwhelming number of part-time adult students who engage in education in a nonlinear progression.

The Bill \& Melinda Gates Foundation and Lumina Foundation are leaders in focusing the national dialogue on student outcomes in post-secondary education. Over the last decade hundreds of colleges and universities have participated in data-driven reform initiatives led by these and other foundations to improve the measurement, analyses, documentation, and achievement of student success. Transformative initiatives include Achieving the Dream (http://achievingthedream.org/about-us), Complete College America (http://completecollege. org), and Completion by Design (http://completionbydesign.org/about-us). Also, not to be forgotten are the early leadership efforts by regional accreditation agencies to require assessment of learning outcomes as part of reaccreditation. As a consequence, the link between documentation of learning outcomes and institutional effectiveness could not be ignored.

Faculty development programs are essential to improve student learning outcomes, but we know that standing alone they are insufficient to dramatically change individual and institutional outcomes in retention, progress, graduation and workforce preparedness. Faculty members and administrators at all levels need to know much more about non-traditional students, gateway courses, prior academic preparation, and current academic decisions in order to link those to student success. In Answering the Call: Institutions and States Lead the Way Toward Better Measures of Postsecondary Performance (Engle 2016), the Gates Foundation calls for the development of a national data strategy and a metrics framework that includes an analysis of performance, efficiency, and equity across issues of access, progression, completion, cost and post-college outcomes. Specific data points populate the grid. To use this framework at the system, state, or institutional level will require accurate and accessible data and new ways of thinking in order to understand student success.

The Association for Institutional Research and institutional research offices across higher education acknowledge the universal and important role that these offices and professionals play in compliance activities. Simultaneously, the personnel working in this area sense that the landscape is changing, not just for institutions, but for the practice of institutional research. Who does it, where is it done, what are the priorities? Will institutional researchers build the collaborative networks and assume leadership for developing a data-informed strategy that will serve important questions about student success at the classroom and campus level? These offices are caught in a quandary as they balance the historical role in compliance with a shift in attention to the role of analytical coordinator and campus leader across multiple internal constituents.

Over the last two years, the Bill \& Melinda Gates Foundation has assisted AIR in addressing these role-related questions with a grant to the association to conduct research and convene experts to explore institutional research capacity and to launch a conversation on the current and future roles of these efforts. The resulting Statement of Aspirational Practice for Institutional Research (Swing and Ross 2016) is intended to generate dialogue and to assist institutional research professionals and offices in thinking about the needs of institutions, constituents, and data to inform student 
success. I am keeping my fingers crossed for the transformation of this field of activity to leadership in institutional analytics!

As you teach, mentor, and advise students and as you serve on curriculum and program committees, I hope you are tapping your institutional research office and other offices for data to inform the important questions of access, progression through majors and minors, graduation, careers, along with other important questions of teaching and learning on your campus. Data informed decisions for student success -now that's a good idea!

\section{References}

Engle, J. (2016). Answering the call: Institutions and states lead the way toward better measures of pstsecondary performance. Seattle, WA: Bill and Melinda Gates Foundation.

Swing, R., \& Ross, L. (2016). Statement of aspirational practice for institutional research. Tallahassee, FL: Association for Institutional Research. Retrieved from https:/www.airweb.org/Resources/ ImprovingAndTransformingPostsecondaryEducation/Documents/Statement $\% 20 \mathrm{of} \% 20 \mathrm{Aspirational} \%$ 20Practice $\% 20$ for $\% 20$ IR.pdf 